\title{
Identificación y caracterización de Aeromonas sp patógenas aisladas de truchas arcoíris (Oncorhynchus mykiss) clínicamente enfermas cultivadas en piscigranjas del Perú
}

\author{
Identification and characterization of pathogenic Aeromonas sp isolated \\ from clinically diseased rainbow trout (Oncorhynchus mykiss) raised in \\ Peruvian fish farms
}

\author{
Jeferson Nuñure O. ${ }^{1}$, Nieves Sandoval C. ${ }^{1,3}$, Mauro Estrella O. ${ }^{1}$, \\ Felipe Ramos E. ${ }^{1}$, Antonio Herrera R. ${ }^{1}$, Adhemir Valera A. ${ }^{1}$, \\ Alberto Manchego S. ${ }^{2}$
}

\section{Resumen}

La investigación tuvo como objetivo la caracterización bioquímica e identificación molecular de cepas patógenas de Aeromonas sp aisladas de truchas arcoíris juveniles con signología compatible a aeromoniasis, cultivadas en seis piscigranjas de los departamentos de Junín (2), Pasco (2), Cajamarca (1) y Ancash (1), Perú. Se seleccionaron 60 truchas juveniles de 4-5 meses, con signología sugerente de brotes de aeromoniasis entre 2017 y 2018 . Se realizó la eutanasia y necropsia y se registraron las lesiones externas e internas presentes. Se efectuó el aislamiento bacteriano de muestras de bazo y riñón anterior en agar TSA y GSP por $24-48$ horas a $25^{\circ} \mathrm{C}$, se caracterizaron las colonias bacterianas mediante pruebas bioquímicas y se identificaron por PCR convencional utilizando cebadores específicos del gen ARNr 16S (Aeromonas spp.), $f_{s t \mathrm{~A}}$ (A. salmonicida) y gyrB (A. hydrophila). Además, se realizó la secuenciación y se confirmó por análisis

\footnotetext{
${ }^{1}$ Laboratorio de Histología, Embriología y Patología Veterinaria, Facultad de Medicina Veterinaria, Universidad Nacional Mayor de San Marcos, Lima, Perú

${ }^{2}$ Laboratorio de Microbiología y Parasitología Veterinaria, Facultad de Medicina Veterinaria, Universidad Nacional Mayor de San Marcos, Lima, Perú

${ }^{3}$ E-mail: nsandovalc@unmsm.edu.pe
}

Recibido: 13 de octubre de 2020

Aceptado para publicación: 5 de mayo de 2021

Publicado: 24 de agosto de 2021

CLos autores. Este artículo es publicado por la Rev Inv Vet Perú de la Facultad de Medicina Veterinaria, Universidad Nacional Mayor de San Marcos. Este es un artículo de acceso abierto, distribuido bajo los términos de la licencia Creative Commons Atribución 4.0 Internacional (CC BY 4.0) [https:// creativecommons.org/licenses/by/4.0/deed.es] que permite el uso, distribución y reproducción en cualquier medio, siempre que la obra original sea debidamente citada de su fuente original 
BLAST (NCBI). Las lesiones externas registradas fueron melanosis, aletas necróticas y hemorrágicas, úlceras en la piel y distensión abdominal. Las lesiones internas fueron hepatomegalia, esplenomegalia y hemorragia petequial en hígado, ciegos pilóricos y grasa peritoneal. Se aislaron 12 cepas en GSP ( 7 de Junín y 5 de Cajamarca), caracterizadas como Aeromonas spp, siendo negativas en las muestras de Pasco y Ancash. Las pruebas bioquímicas determinaron cuatro cepas como Aeromonas salmonicida y ocho como Aeromonas sp móviles, diferenciándose por pruebas de motilidad e indol. La identificación molecular por PCR determinó cuatro cepas $A$. salmonicida procedentes de Junín, una cepa $A$. hydrophila de Cajamarca y siete cepas móviles Aeromonas spp (3 de Junín y 4 de Cajamarca) que fueron negativas a la PCR de $A$. salmonicida y $A$. hydrophila. El análisis BLAST (NCBI) confirmó las cepas A. salmonicida y Aeromonas spp (identidad de 98-100\%); además, la cepa de Cajamarca (identificada como A. hydrophila por bioquímica) presentó identidad de $95.65 \%$ con $A$. hydrophila subespecie dhakensis. En conclusión, Aeromonas salmonicida, A. hydrophila subespecie dhakensis y otras Aeromonas móviles patógenas causan signología asociada a aeromoniasis en truchas arcoiris juveniles en las piscigranjas de Junín y Cajamarca. Es la primera vez que se detecta $A$. hydrophila subsp. dhakensis en el país.

Palabras clave: Aeromonas, Oncorhynchus mykiss, pruebas bioquímicas, PCR, Perú

\section{Abstract}

The present research aimed at the biochemical characterization and molecular identification of pathogenic strains of Aeromonas sp, isolated from juvenile rainbow trout with clinical signs compatible with aeromoniasis in six fish farms in Junín (2), Pasco (2), Cajamarca (1) and Ancash (1), Peru. In total, 60 juvenile trout of 4-5 months were selected, with suggestive signs of outbreaks of aeromoniasis between 2017 and 2018. Euthanasia and necropsy were performed and the external and internal lesions present were recorded. Bacterial isolation of spleen and anterior kidney samples was carried out on TSA and GSP agar for $24-48$ hours at $25^{\circ} \mathrm{C}$, bacterial colonies were characterized by biochemical tests and identified by conventional PCR using specific primers of the 16S rRNA gene (Aeromonas spp.), fstA (A. salmonicida) and gyrB (A. hydrophila), and sequencing was performed and confirmed by BLAST analysis (NCBI). The external lesions were melanosis, necrotic and haemorrhagic fins, skin ulcers and abdominal distention. Internal lesions were hepatomegaly, splenomegaly, and petechial haemorrhage in the liver, pyloric cecum, and peritoneal fat. Twelve strains were isolated in GSP ( 7 from Junín and 5 from Cajamarca), characterized as Aeromonas spp, being negative in the Pasco and Ancash samples. The biochemical tests determined four strains as Aeromonas salmonicida and eight as mobile Aeromonas sp, differing by motility and indole tests. Molecular identification by PCR determined four $A$. salmonicida strains from Junín, one $A$. hydrophila strain from Cajamarca and seven Aeromonas spp mobile strains ( 3 from Junín and 4 from Cajamarca) that were negative to the PCR of A. salmonicida and A. hydrophila. BLAST analysis (NCBI) confirmed the strains A. salmonicida and Aeromonas spp (98-100\% identity). Furthermore, the Cajamarca strain (identified as $A$. hydrophila by biochemistry) presented $95.65 \%$ identity with $A$. hydrophila subspecies dhakensis. In conclusion, Aeromonas salmonicida, A. hydrophila subspecies dhakensis and other pathogenic mobile Aeromonas produce symptoms associated with aeromoniasis in juvenile rainbow trout in the Junín and Cajamarca fish farms. It is the first time that A. hydrophila subsp. dhakensis is detected in the country.

Keywords: Aeromonas, Oncorhynchus mykiss, biochemical tests, PCR, Peru 


\section{INTRODUCCIÓN}

La acuicultura es el sector de producción de alimentos con mayor nivel de crecimiento a nivel mundial. En el Perú, los principales recursos acuícolas son la trucha arcoíris (Oncorhynchus mykiss), los langostinos (Litopenaeus vannamei) y las conchas de abanico (Argopecten purpuratus) (FAO, 2018; PRODUCE, 2018). Una patología que afecta el cultivo de la trucha arcoíris es la aeromoniasis, la cual es ocasionada por bacterias del género Aeromonas sp, y que provoca retraso en el crecimiento, mortalidad de peces y perjuicios económicos significativos (Zepeda-Velásquez, 2015). Las principales especies patógenas involucradas en la aeromoniasis son: Aeromonas salmonicida, agente etiológico de la forunculosis, y Aeromonas hydrophila, patógeno principal en la Septicemia por Aeromonas Móviles (MAS) (Cipriano, 2001; Janda y Abbott, 2010). En el Perú se han aislado cepas de Aeromonas; así, IMARPE (2008) y Baca (2012) aislaron $A$. salmonicida y $A$. hydrophila provenientes de truchas arcoíris clínicamente enfermas de piscigranjas de Junín. Al ser un problema sanitario constante, el Organismo Nacional de Sanidad Pesquera (SANIPES) incluyó la aeromoniasis dentro del Programa de Control de Enfermedades en Animales Acuáticos (SANIPES, 2016).

Las bacterias patógenas Aeromonas sp son cocobacilos gramnegativos que producen una signología que incluye nado errático, letargia e inapetencia, melanosis, lesiones externas (ulceraciones, lesiones necrohemorrágicas de aletas y distención abdominal) e internas (septicemia y hemorragia en diversos órganos) (Noga, 2010). Las investigaciones previas sobre $A$. salmonicida en truchas realizaron aislamiento y caracterización bioquímica de las cepas; sin embargo, aún no se ha identificado molecularmente a A. salmonicida, A. hydrophila y otras Aeromonas patógenas. La diversidad fenotípica y genética de estos patógenos (Cipriano, 2001) reafirma la necesidad de realizar más estudios para controlarlos y prevenirlos. El objetivo del presente estudio fue caracterizar e identificar Aeromonas sp patógenas de truchas arcoíris presentes en varias regiones del país.

\section{Materiales y Métodos}

\section{Tipo y Lugar de Estudio}

El estudio fue de tipo descriptivo, e incluyó seis piscigranjas de truchas arcoíris ubicadas en las regiones de Junín (2), Pasco (2), Cajamarca (1) y Ancash (1) durante 2017 y 2018. El procesamiento de las muestras y la realización de las pruebas bioquímicas y moleculares se realizó en la Sección de Ictiopatología de la Facultad de Medicina Veterinaria, Universidad Nacional Mayor de San Marcos (FMV- UNMSM), en Lima.

\section{Material Biológico}

Se seleccionaron 60 truchas arcoíris juveniles $(O$. mykiss $)$ de cultivo mediante muestreo de tipo no probabilístico (De Blas et al., 2020) provenientes de Junín (20), Pasco (20), Cajamarca (12) y Ancash (8). Se tomó como criterios de inclusión a truchas juveniles de 4 a 5 meses, con signología sugerente de brotes de aeromoniasis (lesiones ulcerosas en la piel, melanosis, necrosis y hemorragias en aletas, distensión abdominal y comportamiento anómalo). En este caso, un muestreo intencionado es adecuado en el diagnóstico de enfermedades en poblaciones de peces que han presentado brotes de enfermedad o mortalidad reciente (Noga, 2010).

\section{Toma de muestras}

Los peces fueron anestesiados siguiendo las recomendaciones de CCAC (2010). Para esto, se realizó baños de inmersión en Eugenol por 3-5 minutos, con dosis de $60 \mathrm{mg}$ disuelto en un $1 \mathrm{~L}$ de agua. El estado de anestesia se confirmó mediante la descoordinación 
Cuadro 1. Pruebas bioquímicas realizadas en colonias resultantes del cultivo de bazo y riñón anterior de trucha arcoíris (Oncorhynchus mykiss) para caracterizar las principales Aeromonas sp

\begin{tabular}{|c|c|c|c|}
\hline \multirow{2}{*}{ Prueba bioquímica } & \multirow{2}{*}{ Sigla } & \multicolumn{2}{|c|}{ Reacción (Buller, 2014) } \\
\hline & & A. salmonicida & A. hydrophila \\
\hline Tinción Gram & GM & - & - \\
\hline Oxidasa & $\mathrm{OX}$ & + & + \\
\hline Catalasa & CAT & + & + \\
\hline Hemólisis $\beta$ & HE $\beta$ & + & + \\
\hline Motilidad & MOT & - & + \\
\hline Pigmento marrón & PM & $\mathrm{v}$ & - \\
\hline Ornitina descarboxilasa & ODC & - & - \\
\hline Lisina descarboxilasa & LDC & $+*$ & + \\
\hline Arginina deshidrogenasa & $\mathrm{ADH}$ & + & + \\
\hline Reducción de nitrato & NIT & + & + \\
\hline Indol & IND & - & + \\
\hline Citrato & CIT & - & $+*$ \\
\hline Urea & URE & - & - \\
\hline Degradación de glucosa & GLU & + & + \\
\hline Degradación de lactosa & LAC & - & - \\
\hline Degradación de manitol & MAN & + & + \\
\hline Degradación de gelatina & GEL & + & + \\
\hline Sulfuro de hidrógeno & $\mathrm{H} 2 \mathrm{~S}$ & - & - \\
\hline
\end{tabular}

(+): reacción positiva; (-): reacción negativa;

$\left(+^{*}\right)$ : positivo en $60 \%$ de las cepas; $(v)$ : reacción variable

en el nado y reducción de la ventilación (opercular). Para el sacrificio de los peces se realizó el corte medular entre el cráneo y la médula espinal. La superficie del pez se desinfectó con torundas y alcohol al 70\% previo a la necropsia. Se realizó una incisión estéril en la superficie del bazo y el riñón anterior, se efectuaron piquetes con asa de siembra bacteriológica estéril, para luego sembrar por agotamiento en placas Petri con agar TSA (Agar de Soja Tríptica) y GSP (Glutamate Starch Phenol Agar). Para la identificación se usaron las siglas: T (trucha), B (bazo), $\mathrm{R}$ (riñón anterior) y se enumeraron según el orden de necropsia de cada espécimen y rotulados con lugar y fecha.

Las placas se transportaron al laboratorio de la FMV-UNMSM a temperaturas entre 10 y $15^{\circ} \mathrm{C}$ dentro de un cooler con geles refrigerantes. Una vez en el laboratorio, las superficies de las placas fueron desinfectadas y se almacenaron en estufa a temperatura de incubación $\left(25^{\circ} \mathrm{C}\right)$ por $24-48$ horas. 
Cuadro 2. Detalles de los cebadores (primers) usados para la detección de Aeromonas salmonicida y $A$. hydrophila de colonias resultantes del cultivo de bazo y riñón anterior de trucha arcoíris (Oncorhynchus mykiss)

\begin{tabular}{|c|c|c|c|}
\hline Especie & $\begin{array}{l}\text { Gen que se busca } \\
\text { amplificar }\end{array}$ & $\begin{array}{l}\text { Cebadores } \\
\left(5^{\prime}-3^{\prime}\right)\end{array}$ & $\begin{array}{c}\text { Tamaño } \\
(\mathrm{pb})\end{array}$ \\
\hline $\begin{array}{l}\text { Aeromonas } \\
\mathrm{sp}\end{array}$ & $\begin{array}{c}\text { ARNr 16S } \\
\text { (Persson et al. 2015) }\end{array}$ & $\begin{array}{l}F w: \text { CGACGATCCCTAGCTGGTCT } \\
R v: \text { GCCTTCGCCACCGGTAT }\end{array}$ & $480 \mathrm{pb}$ \\
\hline $\begin{array}{l}\text { Aeromonas } \\
\text { salmonicida }\end{array}$ & $\begin{array}{c}f_{s t \mathrm{~A}} \\
\text { (Beaz-Hidalgo et al. } \\
\text { 2008) }\end{array}$ & $\begin{array}{l}\text { Fer3: CGGTTTTGGCGCAGTGACG } \\
\text { Fer4: AGGCGCTCGGTTTGGCTATCT }\end{array}$ & $404 \mathrm{pb}$ \\
\hline $\begin{array}{l}\text { Aeromonas } \\
\text { hydrophila }\end{array}$ & $\begin{array}{c}\text { gyrB } \\
\text { (Persson et al. 2015) }\end{array}$ & $\begin{array}{l}F w: \text { AGTCTGCCGCCAGTGGCGAC } \\
R v: \text { CGCCCATCGCCTGTTCGAC }\end{array}$ & $144 \mathrm{pb}$ \\
\hline
\end{tabular}

Luego, las colonias resultantes fueron observadas y se seleccionaron aquellas con características similares a Aeromonas en medios TSA y GSP. Se debe observar colonias blanquecinas y circulares de 2-3 mm, el viraje amarillo del agar selectivo GSP producido por bacterias del género Aeromonas, así como la presentación del pigmento marrón en el medio TSA típico de $A$. salmonicida, aunque no todas las cepas la generan. Para asociar las colonias al género Aeromonas se utilizaron pruebas preliminares como la tinción Gram y las pruebas de oxidasa y catalasa (Buller, 2014).

Las bacterias con características similares a Aeromonas fueron sometidas a pruebas bioquímicas posteriores, siguiendo un esquema de caracterización bioquímica no automatizado conveniente en el estudio de bacterias del género Aeromonas (Buller, 2014) (Cuadro 1). La lectura de los resultados se realizó de 24-48 horas posteriores a la siembra de las pruebas bioquímicas e incubación en estufa $\left(25^{\circ} \mathrm{C}\right)$. Para la elaboración, uso de reactivos e interpretación de las pruebas bioquímicas se emplearon las descripciones de Brenner et al. (2005) y Buller (2014). Se priorizó la caracterización y diferenciación de cepas $A$. salmonicida subsp. salmonicida y de las Aeromonas móviles, principalmente $A$. hydrophila.

\section{Estudio Molecular}

Se realizó PCR convencional para la confirmación de las cepas Aeromonas sp caracterizadas por pruebas bioquímicas. $\mathrm{Se}$ utilizaron cebadores específicos del gen ARNr 16S para identificar cepas Aeromonas sp con un producto de $480 \mathrm{pb}$. Para $A$. salmonicida los cebadores Fer3 (Forward) y Fer4 (Reverse) amplificaron el gen $f s t \mathrm{~A}$ (gen del receptor sideróforo férrico) de 404 pares de base (pb), y para A. hydrophila se emplearon cebadores a partir del gen gyrB (subunidad B de la ADN girasa) con un amplicón de $144 \mathrm{pb}$, como se detalla en el Cuadro 2.

Para la extracción de ADN bacteriano se empleó el kit comercial PureLink Genomic DNA Mini Kit (Thermo Fisher Scientific, USA) y para la ejecución de la técnica de PCR se usó el kit comercial GoTaq Green Master Mix (Promega, USA). Para ambos kits se siguieron las recomendaciones de los fabricantes. 


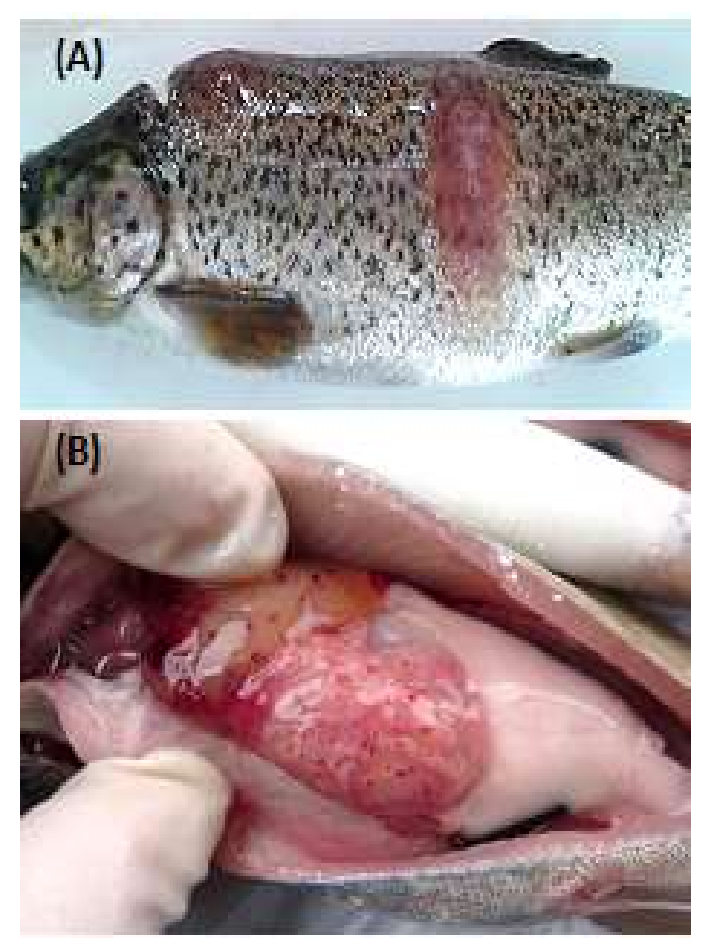

Figura 1. (A) Lesiones externas en truchas arcoíris (Oncorhynchus mykiss): úlceras en piel, lesiones necro-hemorrágicas y distención abdominal; (B) Lesiones internas: hepatomegalia, hemorragia petequial en hígado, ciegos pilóricos y a nivel de grasa peritoneal

Los productos amplificados fueron sometidos a electroforesis ( $90 \mathrm{v}$ durante 1-1.5 horas), utilizando gel de agarosa al $1.5 \%$ en buffer TBE 1X, marcador de peso molecular o «ladder». Adicionalmente se incluyeron controles positivos (cepas de $A$. salmonicida ATCC 33658 y de $A$. hydrophila ATCC 7966) y control negativo «NTC» (agua libre de nucleasas). Las bandas de ADN se visualizaron en un transiluminador (DNR BioImaging Systems, USA).

Se extrajeron y purificaron los productos obtenidos de la PCR de las cepas $A$. salmonicida y A. hydrophila con el kit co- mercial Wizard SV Gel and PCR Clean-Up System (Promega, USA). Los productos se secuenciaron empleando el servicio de Macrogen Inc. (Corea del Sur). Las secuencias obtenidas se alinearon y contrastaron con la base de datos del Centro Nacional para la Información Biotecnológica (NCBI) empleando BLAST (Basic Local Alignment Search Tool).

\section{Consideraciones Éticas}

El estudio contempló las normas éticas para la investigación señaladas por el Comité de Ética y Bienestar Animal de la Facultad de Medicina Veterinaria de la Universidad Nacional Mayor de San Marcos.

\section{Resultados}

Las truchas juveniles fueron seleccionadas por presentar signos clínicos y lesiones asociados a aeromoniasis, lesiones que fueron corroboradas de estar presentes durante la necropsia (Figura 1). Se registraron lesiones externas como melanosis (78.3\%), necrosis de aletas $(68.3 \%)$, ulceraciones epiteliales variadas $(53.3 \%)$, hemorragia petequial o equimótica en aletas $(46.7 \%)$ y distención del abdomen (28.3\%). Asimismo, lesiones internas (Figura 2) como hepatomegalia $(71.7 \%)$, esplenomegalia $(63.3 \%)$, hemorragias petequiales en hígado $(43.3 \%)$ y hemorragias petequiales en ciegos pilóricos $(16.7 \%)$ y grasa peritoneal (16.7\%) (Cuadro 3).

El cultivo y aislamiento bacteriano se efectuó en los medios TSA y GSP. En el medio TSA se obtuvieron 60 cepas bacterianas, de las cuales solo una desarrolló un pigmento color café tenue, tanto en los aislados de riñón anterior como en los de bazo. En el medio GSP, medio selectivo para Aeromonas, se pudo evidenciar el crecimiento de 12 aislados que viraron el medio rojo del agar a un color amarillo evidenciando la presencia de bacterias de este género (Cuadro 4). 
Cuadro 3. Frecuencia de alteraciones patológicas macroscópicas observadas tras la necropsia de 60 truchas arcoíris (Oncorhynchus mykiss) con signología clínica de aeromoniasis

\begin{tabular}{lll}
\hline \multirow{2}{*}{ Alteraciones patológicas macroscópicas } & \multicolumn{2}{c}{ Frecuencia } \\
\cline { 2 - 3 } & $\mathrm{n}$ & $\%$ \\
\hline Externas & 47 & 78.3 \\
Melanosis de la piel & 41 & 68.3 \\
Necrosis de aletas & 32 & 53.3 \\
Ulceraciones epiteliales & 28 & 46.7 \\
Hemorragia en aletas & 17 & 28.3 \\
Distención abdominal & & \\
Internas & 43 & 71.7 \\
Hepatomegalia & 38 & 63.3 \\
Esplenomegalia & 26 & 43.3 \\
Hemorragia petequial en hígado & 10 & 16.7 \\
Hemorragia petequial en ciegos pilóricos & 10 & 16.7 \\
Hemorragia petequial en grasa peritoneal & & \\
\hline
\end{tabular}

En la caracterización fenotípica de aislados del género Aeromonas se apreciaron colonias que presentaban desarrollo rápido (entre 24 y 48 horas), tamaño de $2-3 \mathrm{~mm}$ de diámetro, formas circulares con bordes definidos y coloración blanquecina o cremosa. La tinción Gram permitió la visualización de morfología bacteriana bacilar o cocobacilar y de coloración acidófila o gramnegativa típicas.

Las pruebas bioquímicas de oxidasa y catalasa resultaron positivas para los 12 aislados de Aeromonas que, previamente, habían virado a amarillo el medio del agar GSP. Estas cepas provinieron de muestras de Junín (7 aislados) y Cajamarca (5 aislados), tanto de riñón anterior como de bazo. Todas las cepas Aeromonas sp presentaron similitudes en las siguientes pruebas bioquímicas: oxidasa y catalasa positivas, hemólisis beta en agar sangre, arginina deshidrogenasa positivas, reducción de nitratos, metabolismo de la glucosa, manitol, degradación de la gelatina y ureasa negativa.

Las cepas R3, B4, R14 y R17 de Junín no presentaron motilidad (MOT) en medio SIM y eran indol negativas (presuntivos a $A$. salmonicida), mientras las cepas R5, B19, B20 de Junín y R9, B9, R10, B11 y B12 de Cajamarca eran móviles e indol positivas (característico de Aeromonas móviles). Las cepas Aeromonas sp presentaron resultados que diferían o eran variables para las pruebas bioquímicas: lisina descarboxilasa (LDC), ornitina descarboxilasa (ODC), lactacto (LAC), citrato (CIT) y producción de sulfuro de hidrógeno $\left(\mathrm{H}_{2} \mathrm{~S}\right)$ relacionado a lo descrito por Abbott et al. (2003) y Buller (2014). 
Cuadro 4. Caracterización preliminar de los aislados presuntivos a Aeromonas sp obtenidos de truchas arcoíris (Oncorhynchus mykiss) con signología clínica de aeromoniasis procedentes de Junín y Cajamarca (Perú)

\begin{tabular}{|c|c|c|c|c|c|c|c|c|c|}
\hline \multirow{2}{*}{ Origen } & \multirow{2}{*}{ Especie } & \multirow{2}{*}{ Cepa } & \multicolumn{2}{|c|}{ Desarrollo } & \multirow{2}{*}{ Colonias } & \multirow{2}{*}{ Gram } & \multirow{2}{*}{ Morfología } & \multirow{2}{*}{ OX } & \multirow{2}{*}{ CAT } \\
\hline & & & TSA & GSP & & & & & \\
\hline \multirow{7}{*}{ 䍖 } & \multirow{7}{*}{ 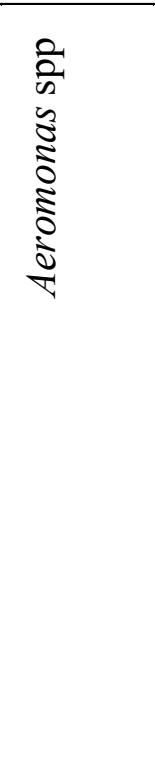 } & R3 & $\begin{array}{c}\text { Sí } \\
\text { SPA }\end{array}$ & $\begin{array}{r}\text { Sí } \\
\text { VA }\end{array}$ & $\begin{array}{l}\text { Circular } 2 \mathrm{~mm} \text {, } \\
\text { blanquecinas }\end{array}$ & - & $\begin{array}{c}\text { Bacilos y } \\
\text { cocobacilos }\end{array}$ & + & + \\
\hline & & B4 & $\begin{array}{c}\text { Sí } \\
\text { PM }\end{array}$ & $\begin{array}{r}\text { Sí } \\
\text { VA }\end{array}$ & $\begin{array}{c}\text { Circular, } 2 \mathrm{~mm} \text {, } \\
\text { blanquecinas }\end{array}$ & - & $\begin{array}{l}\text { Bacilos y } \\
\text { cocobacilos }\end{array}$ & + & + \\
\hline & & R14 & $\begin{array}{c}\text { Sí } \\
\text { SPA }\end{array}$ & $\begin{array}{l}\text { Sí } \\
\text { VA }\end{array}$ & $\begin{array}{c}\text { Circular, } 2 \mathrm{~mm} \text {, } \\
\text { blanquecinas }\end{array}$ & - & $\begin{array}{l}\text { Bacilos y } \\
\text { cocobacilos }\end{array}$ & + & + \\
\hline & & $\mathrm{R} 17$ & $\begin{array}{c}\text { Sí } \\
\text { SPA }\end{array}$ & $\begin{array}{l}\text { Sí } \\
\text { VA }\end{array}$ & $\begin{array}{c}\text { Circular, } 3 \mathrm{~mm} \text {, } \\
\text { blanquecinas }\end{array}$ & - & $\begin{array}{l}\text { Bacilos y } \\
\text { cocobacilos }\end{array}$ & + & + \\
\hline & & $\mathrm{R} 5$ & $\begin{array}{c}\text { Sí } \\
\text { SPA }\end{array}$ & $\begin{array}{r}\text { Sí } \\
\text { VA }\end{array}$ & $\begin{array}{c}\text { Circular, } 2 \mathrm{~mm} \text {, } \\
\text { blanquecinas }\end{array}$ & - & $\begin{array}{l}\text { Bacilos y } \\
\text { cocobacilos }\end{array}$ & + & + \\
\hline & & B19 & $\begin{array}{l}\text { Sí } \\
\text { SPA }\end{array}$ & $\begin{array}{r}\text { Sí } \\
\text { VA }\end{array}$ & $\begin{array}{c}\text { Circular, } 3 \mathrm{~mm} \text {, } \\
\text { blanquecinas }\end{array}$ & - & $\begin{array}{c}\text { Bacilos y } \\
\text { cocobacilos }\end{array}$ & + & + \\
\hline & & $\mathrm{B} 20$ & $\begin{array}{c}\text { Sí } \\
\text { SPA }\end{array}$ & $\begin{array}{r}\text { Sí } \\
\text { VA }\end{array}$ & $\begin{array}{c}\text { Circular, } 2 \mathrm{~mm} \text {, } \\
\text { blanquecinas }\end{array}$ & - & $\begin{array}{c}\text { Bacilos y } \\
\text { cocobacilos }\end{array}$ & + & + \\
\hline \multirow{5}{*}{ 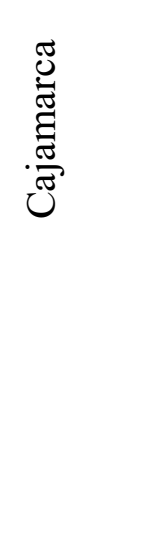 } & \multirow{5}{*}{ 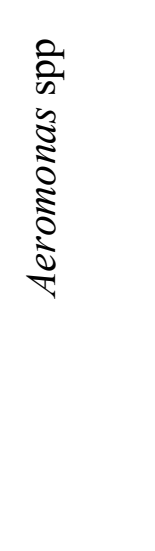 } & B11 & $\begin{array}{l}\text { Sí } \\
\text { NP }\end{array}$ & $\begin{array}{l}\text { Sí } \\
\text { VA }\end{array}$ & $\begin{array}{c}\text { Circular, } 2 \mathrm{~mm} \text {, } \\
\text { blanquecinas }\end{array}$ & - & $\begin{array}{l}\text { Bacilos y } \\
\text { cocobacilos }\end{array}$ & + & + \\
\hline & & R9 & $\begin{array}{l}\text { Sí } \\
\text { NP }\end{array}$ & $\begin{array}{r}\text { Sí } \\
\text { VA }\end{array}$ & $\begin{array}{c}\text { Circular, } 3 \mathrm{~mm} \text {, } \\
\text { blanquecinas }\end{array}$ & - & $\begin{array}{l}\text { Bacilos y } \\
\text { cocobacilos }\end{array}$ & + & + \\
\hline & & B9 & $\begin{array}{l}\text { Sí } \\
\text { NP }\end{array}$ & $\begin{array}{r}\text { Sí } \\
\text { VA }\end{array}$ & $\begin{array}{c}\text { Circular, } 2 \mathrm{~mm} \text {, } \\
\text { blanquecinas }\end{array}$ & - & $\begin{array}{l}\text { Bacilos y } \\
\text { cocobacilos }\end{array}$ & + & + \\
\hline & & $\mathrm{R} 10$ & $\begin{array}{l}\text { Sí } \\
\text { NP }\end{array}$ & $\begin{array}{l}\text { Sí } \\
\text { VA }\end{array}$ & $\begin{array}{c}\text { Circular, } 3 \mathrm{~mm} \text {, } \\
\text { blanquecinas }\end{array}$ & - & $\begin{array}{l}\text { Bacilos y } \\
\text { cocobacilos }\end{array}$ & + & + \\
\hline & & B12 & $\begin{array}{c}\text { Sí } \\
\text { SPA }\end{array}$ & $\begin{array}{r}\text { Sí } \\
\text { VA }\end{array}$ & $\begin{array}{c}\text { Circular, } 2 \mathrm{~mm} \text {, } \\
\text { blanquecinas }\end{array}$ & - & $\begin{array}{l}\text { Bacilos y } \\
\text { cocobacilos }\end{array}$ & + & + \\
\hline
\end{tabular}

$\mathrm{R}=$ Riñón anterior; $\mathrm{B}=\mathrm{Bazo} ; \mathrm{PM}=$ Forma pigmento marrón; $\mathrm{SPA}=$ Sin pigmentación aparente; $\mathrm{NP}=$ No forma pigmentos; $\mathrm{VA}=$ Viraje amarillo; $\mathrm{OX}=0 \mathrm{xidasa} ; \mathrm{CAT}=$ catalasa

La interpretación de los resultados de las pruebas bioquímicas permitió discriminar las cepas de Aeromonas no móviles (como las cepas típicas de $A$. salmonicida subsp. salmonicida) de las Aeromonas móviles (como las cepas de las presuntas $A$. hydrophila, A. veronii y A. bestiarum).
Además, dentro de las cepas caracterizadas como Aeromonas móviles se observaron perfiles bioquímicos similares a cepas de $A$. hydrophila (posteriormente confirmadas mediante técnicas moleculares), así como cepas presuntivas a $A$. veronii y $A$. bestiarum (Buller, 2014). 


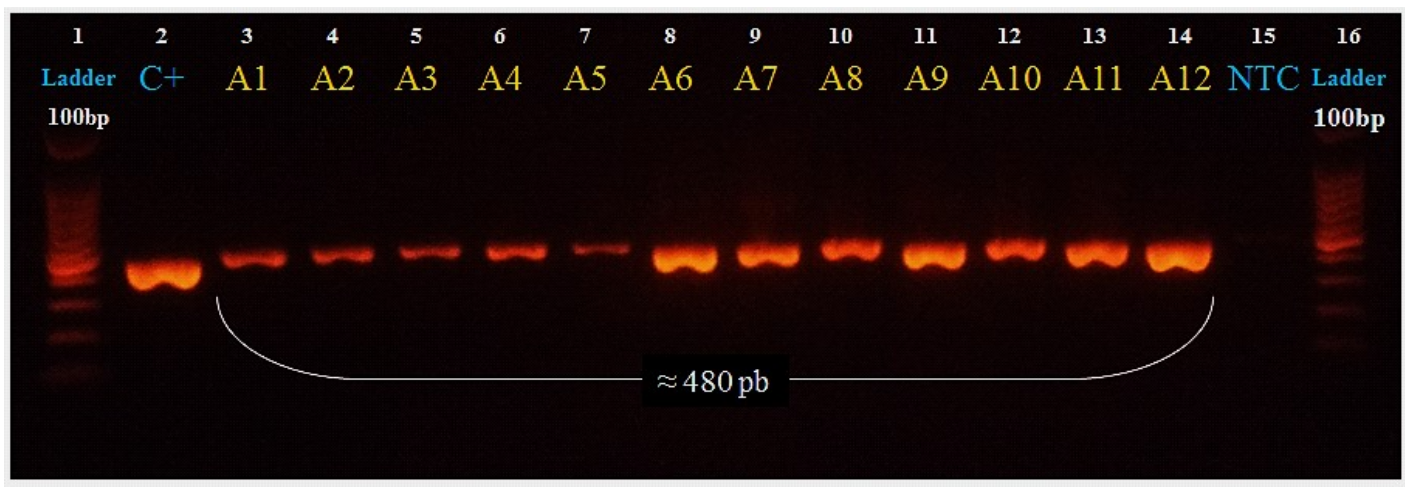

Figura 2. Electroforesis de producto de PCR de aislados Aeromonas sp presenta 12 muestras positivas a Aeromonas sp en columnas 3-14, control positivo de $480 \mathrm{pb}$ en columna 2, control negativo en columna 15 y ladder en columna 1 y 16
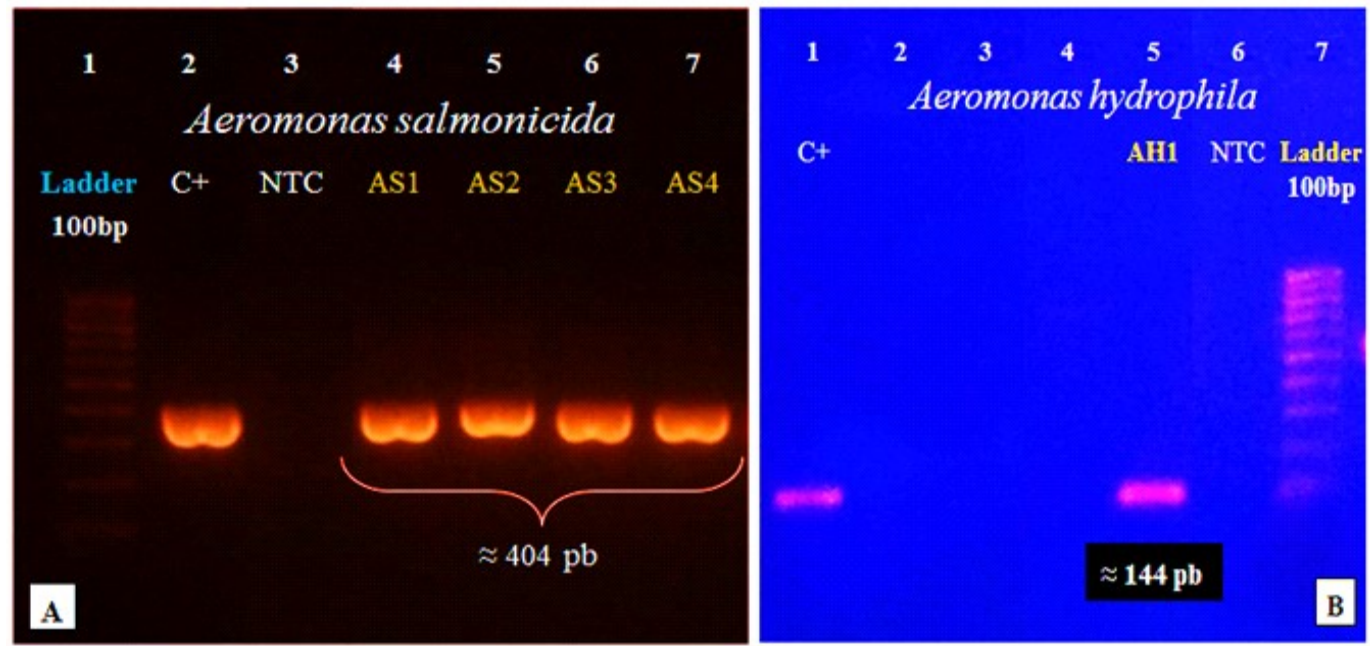

Figura 3. Electroforesis de producto de PCR (A) presenta 4 muestras positivas a $A$. salmonicida en columnas 4-7, control positivo de $404 \mathrm{pb}$ en columna 2, control negativo NTC en columna 3 y ladder en columna 1 ; mientras (B) presenta 1 muestra positiva a $A$. hydrophila, control positivo de $144 \mathrm{pb}$ en columna 1, control negativo NTC en columna 6 y ladder en columna 7

Se realizó PCR convencional a partir de las colonias de las presuntas Aeromonas obtenidas en la caracterización bioquímica. Para la identificación molecular se buscó obtener un producto de $480 \mathrm{pb}$. Para detectar $A$. salmonicida se generó un producto de 404 pb y para $A$. hydrophila un producto de 144 $\mathrm{pb}$. Los resultados indican que siete cepas de Junín (R3, B4, R5, R14, R17, B19 y B20) y cinco cepas de Cajamarca (R9, B9, R10, R11 y B12) se engloban dentro del género Aeromonas (Figura 3). Posteriormente, se 
identificó que las cepas R3, B4, R14 y R17 de Junín fueron positivas a $A$. salmonicida, mientras que la cepa B11 de Cajamarca fue positiva a $A$. hydrophila (Figura 4).

Se realizó el secuenciamiento de los productos de PCR y se realizó el alineamiento mediante el software ClustalX. El análisis bioinformático efectuado a través de BLAST (NCBI) confirmó las cepas Aeromonas spp y $A$. salmonicida utilizando los marcadores moleculares ARNr $16 \mathrm{~S}$ y $f$ st A respectivamente, las cuales mostraron un porcentaje de similitud de 98 a $100 \%$ con las secuencias almacenadas en la base de datos NCBI. Además, la cepa de Cajamarca identificada previamente como $A$. hydrophila mediante pruebas bioquímicas y PCR convencional (empleando el marcador molecular gyrB), evidenció una identidad de $95.6 \%$ con Aeromonas hydrophila subespecie dhakensis con los genes de gyr B presentes en el GenBank.

\section{Discusión}

Esta investigación se orientó principalmente a la caracterización e identificación de cepas patógenas causantes de aeromoniasis en la truchicultura peruana: $A$. salmonicida (forunculosis) y A. hydrophila (Septicemia por Aeromonas móviles). Austin B y Austin D (2007) y Dallaire-Dufresne et al. (2013) indican que este problema sanitario genera retraso en el crecimiento, inmunosupresión, signología diversa, alta morbilidad (80-100\%) y mortalidad (entre 0 y $80 \%$ ). Los experimentos realizados por Zepeda-Velásquez et al. (2017) en México, resaltan la patogenicidad de $A$. salmonicida y $A$. hydrophila.

Las lesiones externas encontradas en la necropsia fueron similares a las descritas por Cipriano (2001), Noga (2010) y Baca (2012). Además, como indica ZepedaVelásquez (2015), las lesiones externas halladas son compatibles tanto para forunculosis como para la septicemia por Aeromonas móviles. De otra parte, las lesiones internas halladas se correlacionan con las descripciones de Roberts (2001), Koziñska (2007) y Baca (2012) en truchas afectadas con aeromoniasis. Las alteraciones más resaltantes son las hemorragias de tipo petequial o equimótica en riñón, bazo, hígado y tracto intestinal, tal y como lo describen Cipriano (2001) y Noga (2010).

Austin B y Austin D (2007) y Koziñska (2007) mencionan que en la patología ocasionada por $A$. salmonicida, no siempre conlleva la formación del forúnculo, sobre todo en infección aguda o subaguda en peces juveniles y en brotes epidemiológicos; lo que coincide con los hallazgos de este estudio. De hecho, A. hydrophila también puede ocasionar lesiones forunculosas (ZepedaVelásquez, 2015). Además, en salmónidos como la trucha arcoíris la presentación de signos clínicos frente a una infección bacteriana cursa con signología general, no patognomónica (Kumar et al. 2015), y que se asemeja a lo ocasionado por Yersinia ruckeri (Sierralta, 2011) o Flavobacterium psychrophilum (León et al., 2008) que cursan con melanosis, esplenomegalia, hepatomegalia, lesiones hemorrágicas multifocales, entre otras anomalías del comportamiento.

La caracterización bioquímica se separó en dos fases. La primera fase buscó aislar cepas Aeromonas spp en agar TSA y GSP (selectivo), y caracterizarlas observando la morfología macroscópica y microscópica, tinción de Gram, prueba de oxidasa y catalasa. Así, 12 cepas de Aeromonas sp provenientes de Junín y Cajamarca se desarrollaron en el agar GSP. El aislamiento de cepas de Aeromonas en la región Junín se correlacionan a lo hallado por IMARPE (2008) y Baca (2012). Sin embargo, hasta el momento no se habían reportado Aeromonas en truchas de cultivo en Cajamarca. La presentación del pigmento marrón soluble en TSA observado en una de las cuatro cepas A. salmonicida, descrito por Baca (2012) y 
Buller (2014), varía por el contenido de triptona y la termolabilidad de la hidroxifenilpiruvato dioxigenasa, según lo descrito por Qiao et al. (2018).

La segunda fase usó un sistema no automatizado para caracterizar bioquímicamente cepas Aeromonas spp y separarlas por especies, ya que los sistemas automatizados aún no discriminan las especies de Aeromonas con las de Vibrio (Janda y Abbott, 2010; Latif-Eugenín, 2016). Además, las Aeromonas presentan una diversidad genética, bioquímica y antigénica que dificulta su caracterización patogénica (Cipriano, 2001). Así, la diferenciación se basó en la prueba de motilidad (en medio SIM) e indol, ya que $A$. salmonicida es una bacteria no móvil e indol negativa, todo lo contrario a las Aeromonas móviles, como A. hydrophila. Se diferenciaron cuatro cepas de Junín presuntivas a $A$. salmonicida y ocho Aeromonas móviles de Cajamarca. Las Aeromonas móviles reaccionaron variablemente a las pruebas ODC, LDC, LAC, CIT y H2S, lo que sugirió la presencia de A. hydrophila, además de perfiles bioquímicos similares a las cepas patógenas A. veronii y $A$. bestiarum como los descritos por Abbott et al. (2003), Baca (2012) y Buller (2014).

Latif-Eugenín (2016) menciona que para la caracterización e identificación de Aeromonas, el Comité Internacional de Sistemática de Procariotas (ICSP) recomienda un estudio polifásico que incluya estudios de fenotipo, genotipo y, actualmente, estudios filogenéticos. Así, Baca (2012) caracterizó bioquímicamente siete cepas $A$. salmonicida y una cepa de $A$. hydrophila de Junín, pero, en el país aún no se han identificado bioquímica o molecularmente otras especies de Aeromonas móviles que afectan las truchas arcoíris de cultivo. Así, en el presente estudio se desarrollaron tres protocolos de detección molecular para Aeromonas sp, $A$. salmonicida y A. hydrophila.
Se emplearon cebadores específicos para la detección molecular de Aeromonas spp (ARNr 16S) y A. hydrophila (gyrB), basándose en el estudio efectuado por Persson et al. (2015). Para el caso de $A$. salmonicida se amplificó el gen $f_{s t} \mathrm{~A}$, diseñado por Beaz-Hidalgo et al. (2008), ya que marcadores moleculares como ARNr 16S o gyr B incluso identifican genotípicamente a otras Aeromonas (Beaz-Hidalgo et al., 2013a). La secuenciación de los productos del PCR y el análisis BLAST (NCBI) confirmaron las cepas $A$. salmonicida y Aeromonas spp, presentando una similitud de 98-100\%, mientras la cepa B11 A. hydrophila de Cajamarca demostró una identidad de 95.6\% con Aeromonas hydrophila subespecie dhakensis, siendo porcentajes de identidad aceptables, como se indica en los estudios de Martínez-Murcia et al. (2009) y Latif-Eugenín (2016).

Este estudio utilizó cebadores para identificar las principales Aeromonas patógenas que afectan la truchicultura, como lo describe Cipriano (2001), Noga (2010) y Baca (2012). Para esclarecer la divergencia genética a nivel intraespecie o interespecie de A. hydrophila y de otras Aeromonas móviles, Martínez-Murcia et al. (2011) recomiendan el empleo de genes como gyr B (empleado en este estudio), rpo $\mathrm{D}, r e c \mathrm{~A}, d n a \mathrm{~J}$, gyrA, dnaX y atpD. Así, Beaz-Hidalgo et al. (2013b) y Colston et al. (2014) empleando estudios filogenéticos reclasificaron $A$. hydrophila subsp. dhakensis en $A$. dhakensis (estrechamente relacionado a $A$. hydrophila). Chen et al. (2016) indican que este microorganismo se distribuye en ambientes acuáticos de áreas tropicales y subtropicales, aislado de muestras de peces y humanos enfermos, demostrando una marcada virulencia para el desarrollo de bacteriemias e infecciones clínicas, descripciones que se asocian a la cepa aislada en Cajamarca.

Las siete cepas de Aeromonas móviles (identificadas como Aeromonas sp) presen- 
taban perfiles bioquímicos similares a las cepas patógenas $A$. veronii y $A$. bestiarum. Esto se conjetura por las diferencias en las pruebas bioquímicas: ODC positivo y LAC negativo como presuntivo a $A$. veronii mientras LAC positivo y $\mathrm{H} 2 \mathrm{~S}$ positivo como presuntivo a A. bestiarum, de acuerdo con lo descrito por Buller (2014). La idea de una infección natural ocasionada por distintas especies de Aeromonas es descrita por Baca en Junín (2012) y se ve reforzada por las descripciones de coinfección en peces de cultivo realizadas por Koziñska y Pekala (2012) y por Zepeda-Velásquez et al. (2015), quienes identificaron molecular e histopatológicamente $A$. salmonicida, A. hydrophila y $A$. veronii cohabitando e infectando truchas arcoíris de cultivo con signos clínicos de enfermedad.

El elevado aislamiento de colonias gramnegativas en medio TSA (42/60) se debió a Yersinia ruckeri, enterobacteria de frecuente presentación en la truchicultura del Perú, causante de yersiniosis («enfermedad de la boca roja») que genera signología similar (melanosis, esplenomegalia, hepatomegalia $\mathrm{y}$ hemorragias multifocales) $\mathrm{y}$ ha sido reportada en diversos estudios (Fernández, 2011; Sierralta, 2011; Sirvas et al., 2011). Así, en la casuística del Laboratorio de Ictiopatología (FMV-UNMSM) se ha identificado $Y$. ruckeri además de Flavobacterium psychrophilum, causante de la enfermedad bacteriana del agua fría, ambas con signología similar; de allí que debe efectuarse el diagnóstico diferencial con estas enfermedades bacterianas, la caracterización por bioquímica y la identificación molecular.

Para concluir, el estudio demostró que distintas especies de Aeromonas causan aeromoniasis en truchas arcoíris en una misma piscigranja, y que puede existir infecciones mixtas, especialmente con Yersinia ruckeri, tornándose un problema sanitario relevante que afecta a la incipiente y poco tecnificada truchicultura nacional. Se precisan más estudios que identifiquen molecularmente, e incluso filogenéticamente, las es- pecies de Aeromonas que afectan el desarrollo de la acuicultura peruana, en especial Aeromonas patógenas de truchas arcoíris.

\section{Agradecimientos}

Los autores manifiestan su agradecimiento a Innovate -Perú por la subvención, la capacitación y el desarrollo del trabajo de tesis del primer autor mediante la ejecución del Proyecto N. ${ }^{\circ} 078$ - INNOVATEPERU - IAPIP - 2017.

\section{Conclusiones}

- Aeromonas salmonicida está presente en las piscigranjas de Junín mientras Aeromonas hydrophila subespecie dhakensis, en las de Cajamarca. Ambas bacterias causan signología asociada a aeromoniasis en las truchas arcoíris juveniles y se presentan en baja frecuencia.

- Se detecta la presencia de otras especies de Aeromonas móviles, distintas a A. hydrophila, en las piscigranjas de Junín y Cajamarca; las cuales están involucradas en el desarrollo de aeromoniasis en truchas arcoíris juveniles y se presentan en baja frecuencia.

\section{Literatura Citada}

1. Abbott SL, Cheung WK, Janda JM. 2003. The genus Aeromonas: biochemical characteristics, atypical reactions, and phenotypic identification schemes. J Clin Microbiol 41: 2348-2357. doi: 10.1128/jcm.41.6.2348-2357.2003

2. Austin B, Austin D. 2007. Bacterial fish Pathogens. Diseases in farmed and wild fish. $4^{\text {th }}$ ed. UK: Springer. $552 \mathrm{p}$.

3. Baca, RF. 2012. Aislamiento e identificación bioquímica de Aeromonas salmonicida en truchas arcoíris (Oncorhynchus mykiss) en fase juve- 
nil en una piscigranja de la región Junín. Tesis de Médico Veterinario. Lima, Perú: Univ. Nacional Mayor de San Marcos. 77 p.

4. Beaz-Hidalgo R, Magi GE, Balboa $S$, Barja JL, Romalde JL. 2008. Development of a PCR protocol for the detection of Aeromonas salmonicida in fish by amplification of the $f_{s t}$ (ferric siderophore receptor) gene. Vet Microbiol 128 (3-4): 386-394.

5. Beaz-Hidalgo R, Magi GE, Balboa $S$, Barja JL, Romalde JL. 2008. Development of a PCR protocol for the detection of Aeromonas salmonicida in fish by amplification of the $f_{s t}$ (ferric siderophore receptor) gene. Vet Microbiol 128: 386-394. doi: 10.1016/j.vetmic.2007.10.004

6. Beaz-Hidalgo $R$, Latif-Eugenín $F$, Figueras MJ. 2013a. The improved PCR of the $f s t \mathrm{~A}$ (ferric siderophore receptor) gene differentiates the fish pathogen Aeromonas salmonicida from other Aeromonas especies. Vet Microbiol 166: 359-363. doi: 10.1016/ j.vetmic.2013.06.028

7. Beaz-Hidalgo R, Martinez-Murcia A, Figueras MJ. 2013b. Reclassification of Aeromonas hydrophila subsp. dhakensis Huys et al., 2002 and Aeromonas aquariorum Martinez-Murcia et al., 2008 as Aeromonas dhakensis sp. nov. comb nov. and emendation of the species Aeromonas hydrophila. Syst Appl Microbiol 36: 171-176. doi: 10.1016/j.syapm.2012.12.007

8. Brenner DJ, Krieg NR, Garrity GM, Staley JT. 2005. The Proteobacteria. Part A: Introductory essays. In: Garrity GM (ed). Bergey's manual of systematic bacteriology. Vol 2. $2^{\text {nd }}$ ed. New York: Springer. 1-304.

9. Buller NB. 2014. Bacteria and fungi from fish and other aquatic animals. A practical identification manual. $2^{\text {nd }}$ ed. UK: CABI. $881 \mathrm{p}$.

10. [CCAC] Canadian Council on Animal Care. 2010. CCAC Guidelines on euthanasia of animals used in science. Ottawa: Canadian Council on Animal Care. 36 p.
11. Chen PL, Lamy B, Ko WC. 2016. Aeromonas dhakensis, an increasingly recognized human pathogen. Front Microbiol 7: 793. doi: 10.3389/ fmicb.2016.00793

12. Cipriano RC. 2001. Aeromonas hydrophila and motile aeromonad septicemias of fish. Fish Dis Leaflet 68: 1-25.

13. Colston SM, Fullmer MS, Beka L, Lamy B, Gogarten JP, Graf J. 2014. Bioinformatic genome comparisons for taxonomic and phylogenetic assignments using Aeromonas as a test case. MBio 5: e02136. doi: 10.1128/mBio.02136-14

14. Dallaire-Dufresne S, Tanaka KH, Trudel MV, Lafaille A, Charette SJ. 2013. Virulence, genomic features, and plasticity of Aeromonas salmonicida subsp. salmonicida, the causative agent of fish furunculosis. Vet Microbiol 169: 1-7. doi: 10.1016/j.vetmic.2013.06.025

15. De Blas I, Muniesa A, Vallejo A, RuizZarzuela I. 2020. Assessment of sample size calculations used in aquaculture by simulation techniques. Front Vet Sci 7: 253. doi: 10.3389/ fvets.2020.00253

16. [FAO] Organización de las Naciones Unidas para la Agricultura y la Alimentación. 2018. El estado mundial de la pesca y la acuicultura 2018. Roma: FAO. 233 p.

17. Fernández C. 2011. Determinación de Yersinia ruckeri y sus características lesiónales anátomo - histopatológicas en truchas arcoíris (Oncorhynchus mykiss) en etapa pre-comercial en una piscigranja de la región Junín. Tesis de Médico Veterinario. Lima, Perú: Univ. Nacional Mayor de San Marcos. 69 p.

18. [IMARPE] Instituto del Mar del Perú. 2008. Anuario científico tecnológico 2008. Callao, Perú: Instituto del Mar del Perú. 176 p.

19. Janda J, Abbott S. 2010. The genus Aeromonas: taxonomy, pathogenicity and infection. Clin Microbiol Rev 23: 35-73. doi: 10.1128/CMR.00039-09 
20. Koziñska A, Pekala A. 2012. Characteristics of disease spectrum in relation to species, serogroups, and adhesion ability of motile aeromonads in fish. Sci World J 2012: 949358. doi: $10.1100 / 2012 / 949358$

21. Koziñska A. 2007. Dominant pathogenic species of mesophilic Aeromonads isolated from diseased and healthy fish cultured in Poland. J Fish Dis 30: 293301. doi: 10.1111/j.1365-2761.2007.00813.x.

22. Kumar G, Menanteau»Ledouble S, Saleh M, El»Matbouli M. 2015. Yersinia ruckeri, the causative agent of enteric redmouth disease in fish. Vet Res 46: 2-6. doi: 10.1186/s13567-015-0238-4

23. Latif-Eugenín FL. 2016. Aeromonas, un microorganismo ambiental de importancia en salud humana y animal. Tesis Doctoral. España: Universitat Rovira I Virgili. $391 \mathrm{p}$.

24. León J, Avalos R, Ponce M. 2008. Flavobacterium psychrophilum y su patología en alevines de Oncorhynchus mykiss del centro piscícola El Ingenio, Huancayo. Rev Peru Biol 15: 117-124.

25. Martinez-Murcia A, Monera A, Alperi A, Figueras MJ, Saavedra MJ. 2009. Phylogenetic evidence suggests that strains of Aeromonas hydrophila subsp. dhakensis belong to the species Aeromonas aquariorum sp. nov. Curr Microbiol 58: 76-80. doi: 10.1007/s00284008-9278-6

26. Martinez-Murcia AJ, Monera A, Saavedra MJ, Oncina R, LopezAlvarez M, Lara E, et al. 2011. Multilocus phylogenetic analysis of the genus Aeromonas. Syst Appl Microbiol 34: 189-199. doi: 10.1016/j.syapm.2010.11.014

27. Noga EJ. 2010. Fish disease, diagnosis $\&$ treatment. $2^{\text {nd }}$ ed. USA: WileyBlackwell. 410 p.
28. Persson S, Al-Shuweli S, Yapici S, Jensen JN, Olsen KEP. 2015. Identification of clinical Aeromonas species by rpo $\mathrm{B}$ and gyr $\mathrm{B}$ sequencing and development of a multiplex PCR method for detection of Aeromonas hydrophila, A. caviae, A. veronii, and A. media. J Clin Microbiol 53: 653-656. doi: 10.1128/JCM.01963-14

29. [PRODUCE] Ministerio de la Producción. 2018. Anuario estadístico pesquero y acuícola 2016. Lima: PRODUCE. 202 p.

30. Qiao Y, Wang J, Wang H, Chai B, Rao C, Chen X, Du S. 2018. 4-Hydroxyphenylpyruvate dioxygenase thermolability is responsible for temperature-dependent melanogenesis in Aeromonas salmonicida subsp. salmonicida. Appl Environ Microb 85: e01926-18. doi: 10.1128/ AEM.01926-18

31. Roberts RJ. 2001. Fish pathology. $3^{\text {rd }}$ ed. London: WB Saunders. $472 \mathrm{p}$.

32. [SANIPES] Organismo Nacional De Sanidad Pesquera. 2016. Programa oficial de vigilancia y control de enfermedades en animales acuáticos: P01SDSNA-SANIPES. [Internet]. Disponible en: https://www.sanipes.gob.pe

33. Sierralta V. 2011. Estado situacional de Yersinia ruckeri causante de «la enfermedad entérica de la boca roja» en trucha arcoíris Oncorhynchus mykiss (Walbaum, 1792) en piscigranjas de la sierra central del Perú. Tesis de Maestría. Lima, Perú: Univ. Nacional Mayor de San Marcos. 78 p.

34. Sirvas S, Sánchez C, Peña C. 2011. Diagnóstico e identificación rápidos por PCR de Yersinia ruckeri aislada de Oncorhynchus mykiss procedentes de Canta, Lima, Perú. Rev Peru Biol 18: 349-353. doi: 10.15381/rpb.v18i3.451

35. Zepeda-Velásquez AP. 2015. Aeromonas spp.: la infección en la trucha arcoíris (Oncorhynchus mykiss) y su aislamiento en México. AquaTIC 42: 1-16. 
36. Zepeda-Velásquez AP, Vega-Sánchez V, Salgado-Miranda C, SorianoVargas E. 2015. Histopathological findings in farmed rainbow trout (Oncorhynchus mykiss) naturally infected with 3 different Aeromonas species. Can J Vet Res 79: 250-254
37. Zepeda-Velázquez AP, Vega-Sánchez V, Ortega-Santana C, Rubio-Godoy M, Montes de Oca-Mira D, SorianoVargas E. 2017. Pathogenicity of Mexican isolates of Aeromonas sp in immersion experimentally-infected rainbow trout (Oncorhynchus mykiss, Walbaum 1792). Acta Trop 169: 122-124. doi: 10.1016/j.actatropica.2017.02.013 